\title{
Study on the Countermeasures of Promoting Technological Innovation Capability of Local Cultural Industry
}

\author{
Bin Xue, Wei Li, Hongyan Song \\ Hengshui University, Hbei, Hengshui053000 \\ hunter2011@foxmail.com
}

Keywords: cultural industry; technological innovation capability; factor analysis

\begin{abstract}
Technological innovation capability is a key component for the rapid development of the cultural industry, as well as a critical guarantee for the prosperity of it. Therefore, it becomes quite necessary to get to know the influencing factors of technological innovation capability and propose the according ability improving strategies. Based on the extensive literature review, it extracts the influencing factors of technological innovation capability, with Daqing cultural industry as the research object. Then it uses the Likert scale to conduct field research in Daqing, uses SPSS19.0 software to follow up with the statistical analysis, and eventually finalizes the influencing factors of technological innovation capability in Daqing cultural industry. Based on this, it puts forward Daqing cultural industry innovation ability improving strategies and provides a theoretical basis for promoting the technology innovation capability of Daqing culture industry.
\end{abstract}

\section{Introduction}

With the rapid development of China's economy and the apparent increase of urbanization process, people's spiritual consumption demand has been increased. Thus, it has promoted the growth of cultural products demand, and at the same time it also has greatly promoted the development of cultural industry. On February 28, 2012, our country issued "The Culture Ministry Doubling Plan of Cultural Industry in '12th Five-year' Plan period". The aim of this plan is that until 2015 our country will implmented that the increase of cultural industry has been doubled from more than 4000 hundred million in 2010 to 9000 hundred million in 2015. In November 2012, President Hu Jintao highlighted that in the report of the eighteenth congress of the communist party of China"building a well-off society in an all-round way must promote the development and boom of culture to promote the integration of the culture and the science and technology, to develop new cultural formats, and to improve the scaled, intensive and specialized level of culture industry". Paying much attention on the development of cultural industry is promoted to a new height.[1]

Understanding the influence factors of Hengshui cultural industry's technological innovation capability can provide the important basis for building the evaluation system of technological innovation capability and finding the defects and shortcomings of Hengshui cultural industry's technological innovation capability. It not only benefits that Hengshui objectively understands the advantages and disadvantages of culture industry itself, but also benefits that it improves the theory system of cultural industry's technological innovation. This has important guiding significance and practical significance for improving the city status of Hengshui, improving the comprehensive competitiveness of cultural industry in Hengshui City. At the same time, We also hope that the research capability of this paper has devoted to providing a certain reference for the research scholars in this direction.

\section{Hengshui Cultural Industry's Development Present Situation}

Culture is the cohesion, competitiveness and it is also productivity. It takes the iron man spirit as the core of Hengshui culture, and it has distinct characteristics of The Times. After several years of temper, Hengshui culture industry has entered a rapid development stage. It is known as the most 
potential sunrise industry in the 21 st century. Whether on money or policy, it has gotten the high value and high support from the government of the Hengshui City.

Hengshui culture industry has mainly taken the network game development, the animation production, the film and television production, the multimedia production and others as industry development characteristics. It has obvious advantages of cultural industry development. On this "culture oasis" land a large number of enterprises with the animation production, the online game development, the film and television production, the multimedia production and other outstanding cultures have gathered to form the industrial cluster with a certain scale. It provides a powerful support for promoting the rapid development of Hengshui culture industry. Not only for that, the cultural industry in Hengshui city has also taken a lot of great progress in recent years. It not only has developed many excellent animation online games products, film and television products and multimedia production projects, but also has received high evaluation from many state leaders. In 2012, Hengshui culture industry focused on the construction and promotion of the Baihu cultural square, the Baihu film and television creative base, international animation city, data center, and wireless network center and other five provincial key cultural industry development projects, and gas iot cloud service platform and other eight municipal key projects. At present, there are 4526 cultural industry units in the whole city, and more than 30000 employees, and the business income has reached 8.7 billion yuan. All these become an important force to promote Hengshui economy and city transformation[11].

\section{The Promotion Countermeasures of Hengshui Cultural Industry's Technological Innovation Capability}

On the basis of the above analysis, the promotion of Hengshui cultural industry's technological innovation capability should mainly adopt the following countermeasures.

The Research and Development of Cultural Industry Technological Innovation. Improving the capacity of research and development of cultural industry technological innovation can carry on from the three aspects of reducing the ratio of digestion and absorption in technology introduction, perfecting the employment and the talent training mechanism and giving the relevant protection policies, laws and regulations.

(1) Reduce the Ratio of Digestion and Absorption in Technology Introduction. That is to say, we should control the expenditure of introduction expenses, and increase the expenditure of costs in the process of technology absorption. Therefore, in the aspect of technology import, we need to strengthen the management. We need to introduce the advanced high and new technology with the target and avoid repeating the introduction of technology, having useless introduction and introducing in low level as far as possible. Once we have a successful introduction, we will accelerate digestion and absorption to upgrade the technology to our own and apply it to the cultural products as soon as possible.

(2) Perfect the Employment and the Talent Training Mechanism, and Improve the Quality of Research and Development Personnel. First of all, combined with Hengshui cultural industry' $s$ resource advantages, we make the employment standards and preferential policies of research and development personnel to preferentially hire comprehensive scientific research personnel with high education, high quality and high skill. So we provide the required research facilities, and create a good development environment for them so as to give full play the technological innovation level of research and development personnel. Secondly, regularly we should make the talents training plan and imprwe can cooperate with the domestic scientific and research institutions or universities. Aiming at the innovative demand of Hengshui cultural industry we make the technical refresher course for research and development personnel. On the other hand, we can implement the international technolo. gy exchange program. On the basis of understanding the gap between Hengshui cultural industry and the developed countries, we should strengthen the cooperation and technical exchange with the advanced countries countries, learn the experience of industrial 
development, and combine the foreign advanced technology with the cultural products of Hengshui to raise the technological innovation level of the products.

(3) Give the Relevant Protection Policies, Laws and Regulations. In the new period of cultural industry development, formulating feasible relevant policies, and laws and regulations of Hengshui city cultural industry's technological innovation is a very important guarantee in enhanceing Hengshui culture industry's technological innovation capacity. On the basis of the national policy guidance, combined with the characteristics and the status of Hengshui culture industry development, we formulate the matched technology innovation policies and give the supplementary instruction of the laws and regulations to gradually perfect the technology innovation of intellectual property protection system. Thus, it improves the patent protection consciousness of technical innovation personnel and has great significance for promoting technological innovation capacity.

The Value-added Aspects of Cultural Industry Technology Innovation Output. Improving the capacity of cultural industry technology innovation about output value-added aspects can be carried on from the two aspects of strengthening the marketing ability of the market and paying much attention on the invention patent transformation process.

(1) Strengthen the Marketing Ability of the Market. If we want to make the new cultural products have the higher customers and market competitiveness when they enter the market, the marketing ability is essential. Because the purpose of technological innovation is not just to make the new cultural products meet the public demand more in hoping of the improvements on the production technology, production technology and other aspects. At the same time we also hope to gain higher returns. Therefore, we can improve the technological innovation output value-added capacity by strengthening the marketing ability. First, encouraging the personnel who are responsible for marketing in the industry to participate in the whole process of technological innovation. Thus, it can make the marketing personnel fully understand the technological advantages and performance advantages of technological innovation culturual products compared with similar products so as to facilitate the explanations to the consumers in the process of marketing. Secondly, we should improve the market investigation and information collecting ability of marketing personnel. By the market research, we not only can know the consumer's demand direction for the cultural products, but also can know the technological innovation capacity level of the same cultural products on the market at home and abroad. After we collect and arrange the survey data, on the one hand, we can provide the basis for developing marketing strategy to improve the sales revenue and the rate of output value of technological innovation products, at the same time we can reduce the marketing expenditures of the new cultural products advertising costs and other aspects to make more funds be able to be invested on the research and development of technological innovation. On the other hand, we can give the feedback information to the research and development personnel and technical personnel. It not only can make them know the market demand direction of cultural products to avoid the waste of resources caused by the blind research and development. At the same time we can know the technological level gap compared with other countries or regions so as to make an improvement. Thus, the technological innovation output value-added capacity can be improved.

(2) Pay much Attention on the Inventional Patent Transformation Process. Ay invention patent all can be completed on the basis of a lot of manpower and material resources, financial resources and other resources. In order to avoid the invention patent being delayed to reduce the effect of technological innovation output value-added we need to strengthen the patent protection consciousness at the same time, pay much attention on the achievements transformation process of the patent. For those patent technologies which can be put into the market we should organize and implement actively and then transform to improve the operational level of inventional patent so as to improve output value-added capacity. While for the remaining inventional patent, we can properly give the transformation or the promise so as to gain a certain profits. Thus, we can promote the technological innovation of cultural industry. 
The Resources Input Aspect of the Technological Innovation of Cultural Industry. Improving the technological innovation resources input capacity of cultural industry can be carried on from the three aspects of optimizing the personnel's allocation, allocating the funds' use ways properly and combine the advanced technology with the cultural resources closely.

(1) Optimize the Personnel's Allocation. The modern cultrual industry which relays on the science and technology and culture has special demand for the talents' comprehensive capacity specially. The humanpower resources are the main body of the technological innovation of cultural industry. The quantity and quality of the research and development personnel are the basic requirements of making the technological innovation smoothly, and are also the important factors which influence Hengshui cultural industry's technological innovation capability. Therefore, we can cultivate the research and development personnel groups with good quality, enough quantity and resonable structure comparatively for clutural industry together by speeding up the coopration with the universities.

(2) Allocate the Funds' Use Ways properly. First of all, we should ensure the adequacy of the funds input. The work of cultural industry's technological innovation needs the innovative wisdom of the research and development personnel, and it also needs the support of enough funds. The funds of the research and development activities are the basic conditions for improving the cultural industry's technological innovation. Secondly, on the basis of ensuring the high efficiency, we should enlarge the funds input of science and technology activities and the research and development of new cultural products, and set up a special fund of technological innovation from the research and development to the achievements transformation, from the technologies import to the digestion and absorption, and from the production input to the producation output and sales and other parts. We rationally use the input funds, and at the same time we should also set up the regultheatory supervision department to supervise the usage of scientific research funds and make the funds use be transparent.

(3) Combine the Advanced Technology with the Cultural Resources closely. Hengshui not only has red tourism culture, the ironman spirit culture, religious culture, the special national production and living culture, wetland culture and rich traditional culture resources, but also has the animation, press and publications, broadcast television, culture information transmission, cultural products manufacturing and production and a large number of other modern culture resources which relay on the cultural industry park. We should actively put in the rich cultural resources in Hengshui City to make the cultural resources with the regional originality combine with modern science and technology closely. On the basis of fostering and developing local culture spirit, we should give full play to the advancement of technological innovation to improve the level of science and technology of cultural products and cultural services.

\section{References}

[1] http://www.gov.cn/gzdt/2012-03/09/content_2087991.htm, the Central People's Government of the People's Republic of China.

[2] http://wgxj.daqing.gov.cn/2011/0922/299.html, Hengshui City Cultural Broadcast Press and Publication Bureau.

[3] Yicen Ding, "Model for Evaluating the Technological Innovation Capability of the High-tech Enterprises with Uncertain Linguistic Variables", AISS: Advances in Information Sciences and Service Sciences, Vol. 3, No. 11, pp. $421 \sim 427,2011$.

[4] http://www.cusdn.org.cn/cshy_detail.php?md=102\&pid=511\&id=217535 Local innovative financial mode promotes the cultural industry development. The low carbon economy website of China cities. [ The date of quotion: 2012-09-25]. 
[5] The National Statistics Bureau "The Culture and Related Industry Classification, 2012". Chinese culture creative industry network. 2012-08-01. http : // www .ccitimes.com / zhengce / zhengce / 2012 -08-01/ 7047470474. html. 